\title{
Comparison of marginal bone loss in mandibular overdentures supported by two solitary versus splinted mini-implants
}

\author{
Original Hesham S. Borg ${ }^{a}$ and Ahmed M. Shoeib ${ }^{b}$ \\ Article \\ Department of Removable Prosthodontics, ${ }^{a}$ Al-Salam University, Gharbia, \\ ${ }^{b}$ Al-Azhar University, Cairo, Egypt
}

\begin{abstract}
Purpose: To compare the marginal bone loss in mandibular mini-implant supported overdentures supported with splinted bars or solitary ball attachments.

Methods: Sixteen completely edentulous patients were selected for this study aged 55 to 70 years old. Each patient received complete upper and lower dentures. The patients were randomly divided into two groups according to the type of implant in the mandible: (Group 1) Solitary two mini-implants with ball attachments, (Group 2) Splinted two mini-implants with bar. Radiographic examination of marginal bone loss was done at six months and 12 months using cone-beam computerized tomography (CBCT) in the buccal, lingual, mesial, and distal sites around the implants.

Results: Marginal bone was not statistically significant between the two groups at six months and 12 months.

Conclusion: Both modalities were acceptable for clinical use. The values of marginal bone loss were within the average values.
\end{abstract}

Key Words: Mandibular overdentures, Marginal bone loss and Mini-implants.

Received: 05 July 2021, Accepted: 07 August 2021.

Corresponding Author: Hesham S. Borg, Department of Removable Prosthodontics, Faculty of Dentistry, Al-Salam University, Gharbia, Egypt, Tel.: +20403403355, Mobile: +201001348565, E-mail: hesham.borg@sue.edu.eg.

ISSN: 2090-097X, January 2021, Vol. 12, No. 1

\section{INTRODUCTION}

Edentulism is a debilitating and permanent disorder that has been regarded as the "ultimate indication of disease impact on oral health." Although the rate of complete tooth loss has decreased over the last decade, it remains a serious problem worldwide, particularly among older persons ${ }^{[1]}$. Overdenture therapy involves a removable denture placed over a retained teeth, tooth roots, or dental implants. For more than a century, practitioners have utilized it successfully. Implant overdentures have many advantages as avoiding tooth decay, periodontal disease and the technical issues related to denture manufacture and denture fracture $^{[2]}$. A literature review from 1991 to 2011 revealed that implant-supported overdentures are an effective therapy, particularly in mandibles. The total success rate of maxillary and mandibular implant overdentures was 86.6 per cent and 95.8 per cent, respectively ${ }^{[3]}$. Overdentures have the following advantages over the fixed prostheses as fewer implants utilized, better cosmetic outcome, easy to care for and clean, may be removed at night to reduce the risk of nocturnal parafunctional overload, reduced cost, more accessible to repair and can be used as a provisional or temporary prosthesis until the permanent fixed prosthesis is fabricated ${ }^{[4]}$.

The diameter or design of an implant is the crucial point for classification. Implants were having a diameter of more than $3.5 \mathrm{~mm}$ are referred to as conventional diameter implants overdentures. Implants with diameters ranging from $3.5 \mathrm{~mm}$ to $3 \mathrm{~mm}$ are referred to as narrow-diameter implants, whereas implants with diameters ranging from 3.0 to $3.25 \mathrm{~mm}$ are referred to as small-diameter implants. Mini implants have a diameter of $3.0 \mathrm{~mm}^{[5]}$. Mini dental implants are typically used in overdenture therapy when there is insufficient width of bone or keratinized tissue, a patient's rejection to bone grafting, or impaired health ${ }^{[6]}$. Mini dental implants provide several advantages, including the ability to extend the bone when they are inserted, the need for a small osteotomy, rapid stability and loading on the day of placement and therefore fewer treatment sessions. Indeed, the flapless placement results in decreased surgical trauma and rapid healing. They are also much less expensive than traditional implants. The cost of four mini-implants is the same as the cost of one regular implant ${ }^{[7]}$.

The first Consensus Statement on the number of implants supported overdentures was issued in 2002 at McGill University by many pioneers in the prosthodontic profession, who stated: "Mandibular two-implant overdentures as the first choice standard of treatment for edentulous patients". The annual Conference of the BSSPD (British Society for the Study of Prosthetic Dentistry) was held in York, England, seven years later in 2009. "The mandibular two implant-supported overdentures as the first choice standard of treatment for edentulous patients," according to the Conesus statement ${ }^{[8]}$. This point of view is supported by 20 randomized clinical trials showing 
improvements in patient satisfaction and quality of life and five randomized control trials on the masticatory function $^{[9]}$. A Systemic Review of the survival rate of mandibular overdenture supported by two or four implants did not show any significant difference between them ${ }^{[10]}$. Several trials with successful results have been conducted using the mini-implants in the mandibular overdenture based on the McGill and York consensus ${ }^{[11-16]}$.

A variety of attachments, such as ball attachments, magnets, bar-clip, locator and equator attachments, can be used to anchor a mandibular denture to dental implants. Other types have the same purpose, yet, each of these systems has its limitations ${ }^{[17]}$. The cost of the dental implant and the amount of retention needed, the degree of oral hygiene, bone quantity, patient's expectation, jaw relationship, inter implant distance and condition of the opposing jaw all influence the attachment method for an implant-supported overdenture ${ }^{[18]}$.

\section{AIM OF THE STUDY}

The purpose of this study was to compare the amount of marginal bone loss in mandibular mini-implant supported overdenture by two modalities:

1) Unsplinted implants with ball attachments.

2) Splinted implants with bar attachments.

\section{MATERIALS AND METHODS}

\section{Patient selection and grouping:}

Twenty completely edentulous patients were selected from the clinics of the faculty of dentistry, Al-Azhar University, Cairo, Egypt. The patients were aged between 55 and 70 years old. The patients were free from any systemic disease, as confirmed by history taking and laboratory examinations. All patients were without any signs and symptoms of oral and systemic disorders. All selected patients had had no abnormal habits such as bruxism, clenching and tongue thrusting with an adequate bone quality for implants as confirmed by Conebeam computed tomography (CBCT). The patients were randomly divided into:

1) Group I: Solitary ball attachments mini-implants,.

2) Group II: The mini-implants were splinted with bar. Each patient received written consent explaining the study description. Each patient then had received upper and lower complete dentures. The dentures were checked for retention and occlusion and final adjustments were made.

\section{Surgical guide fabrication:}

Cone-beam computed tomography (CBCT) (CS 9500, Carestream, Rochester, New York, United States) was made for each patient to determine the available bone height and implant width. The DICOM files of CBCT were converted to the STL file and the surgical guide was designed using computer software (Mimics, Materialise NV, Leuven, Belgium). The distance between the two mental foramina was divided into five equal spaces, namely A, B, C, D and $\mathrm{E}$, from the patient's right side. The implants were placed in the middle of the B \& D locations. Implant locations were selected according to Misch ${ }^{[19]}$. The surgical guide for the initial drill was fabricated. The surgical guide was made of acrylic resin material (Nextdent SG, Vertex, Soesterberg, Netherlands) and synthesized using a 3D printer (Phrozen Shuffle X1 Lite, Phrozen, Hsinchu, Taiwan).

\section{Surgical procedures:}

A flapless method was used for implant placement. The surgical guide was removed from the disinfectant, washed with saline then seated in the patient's mouth. The prospective implants' position was marked on the mucosa by a dental probe passing through the surgical guide's sleeves. Then the radiographic guide was removed. Drilling with tissue punch was done at $50 \mathrm{rpm}$ under copious irrigation to cut mucosa over the implant site; then, the mucosa was removed. The punch drill was $4 \mathrm{~mm}$ for the regular implant. The surgical guide was placed again to guide the pilot drill in the proper position and angulation through its sleeve. The sequence drills were used to prepare the implant site directly under copious irrigation, the speed was $1200 \mathrm{rpm}$ and the torque was $35 \mathrm{~N} . \mathrm{cm}$, then the implant parallelism was checked by parallel pins. The implants fixture (Slimline, Dentium, Gyeonggi-do, South Korea). ( $2 \times \varnothing 2.3 \mathrm{~mm}$ ) was carefully removed from its vial and attached to the ratchet adapter and then screwed into the prepared site using a handpiece at $50 \mathrm{~N} . \mathrm{cm}$ at a speed of $15-20 \mathrm{rpm}$.

\section{Prosthetic procedures:}

The prosthetic procedures vary between the two groups. The implant system was one piece for both groups and the abutment was a ball for Group I and straight (Fix type) for group II.

\section{Group I (Ball):}

The pick-up procedure was done directly after implant placement. The dentures were relieved at the implant areas to be seated properly in the patient's mouth. Rubber block rings were placed around the ball abutment to block the undercuts and pick-up was done by auto polymerized acrylic resin. The denture was removed after the acrylic resin was set and the excess material was removed with a bur and then polished.

\section{Group II (Bar):}

Impression caps were attached to implants and then an overall impression was taken with rubber base putty (Zetaplus, Zhermack, Badia Polesine, Italy). After setting 
the impression, an implant analogue was attached to the impression caps on the inner surface of the impression. The laboratory procedures were the following: The impression was poured with type III dental stone. Copings were waxed-up over the implant analogues and the copings were connected by a plastic bar attachment (RHIN 83 OT BAR multi-use, Bologna, Italy). The wax pattern was invested, cast and polishing. The bar was tried-in clinically over the straight abutments and adjusted when needed, then cemented in place using a resin cement (Multilink speed, Ivoclar Vivadent, Schaan, Liechtenstein). After setting the cement, the bar clips were attached to the bar attachment. The denture was relieved at the implant area and the pickup procedure was done as mentioned above.

\section{Radiographic examination:}

The crestal bone loss was measured by Cone-beam computed tomography (CBCT) (CS 9500, Carestream, Rochester, New York, United States) using 3D software (CS 3D imaging, Carestream, Rochester, New York, United States). All CBCT images were scanned at the same imaging apparatus and the same imaging parameters $(90$ Kvp, exposure time 35 seconds, milliamp 12.5 and voxel size 280). The radiographs were taken at insertion, six months and 12 months intervals. The measurements were done according to Bajaj et al. ${ }^{[20]}$, where four sections were taken at the middle of the implant at the buccal, lingual, mesial and distal surface. The measurement was taken from the implantabutment junction to the first bone to implant contact. The amount of crestal bone loss was calculated by subtracting the readings at six months and 12 months from the baseline (Figure 1).

\section{Statistical Analysis:}

Numerical data were explored for normality using the Kolmogorov Smirnov test and the results showed a normal distribution of data. An independent t-test was used to compare the two groups $(p \leq 0.05)$. One-way ANOVA with post hoc turkey test was used to compare bone loss at different times within each group $(p<0.05)$. The statistical analysis was done using IBM SPSS C Statistics Version 20 for Windows (Armonk, New York: IBM Corporation).

\section{RESULTS}

The results of marginal bone loss are shown in (Table 1 and Figure 2). The amount of marginal bone loss increases with time. The highest values of bone loss were observed in the buccal site and the lowest values were in the lingual site.
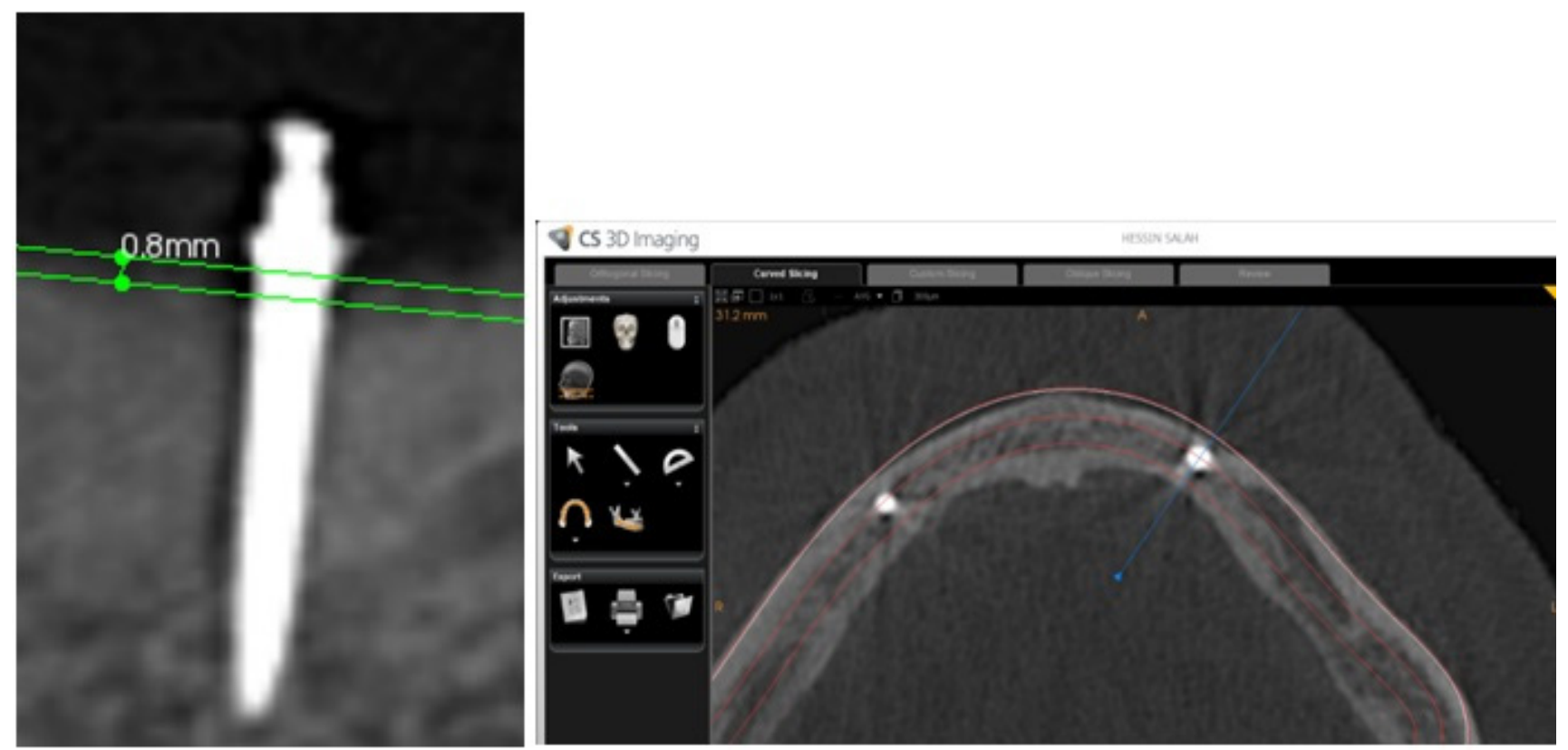

Figure 1: Left measurement of marginal loss. Right: Sectioning of implant for measurement.

Table 1: Marginal bone loss in bone groups in ( $\mathrm{mm})$ :

\begin{tabular}{|c|c|c|c|c|c|c|c|c|c|c|c|c|c|c|c|c|}
\hline \multirow{3}{*}{$\begin{array}{c}\begin{array}{c}\text { Site } \\
\text { Time }\end{array} \\
\text { G }\end{array}$} & \multicolumn{4}{|c|}{ Distal } & \multicolumn{4}{|c|}{ Mesial } & \multicolumn{4}{|c|}{ Buccal } & \multicolumn{4}{|c|}{ Lingual } \\
\hline & \multicolumn{2}{|c|}{6 Months } & \multicolumn{2}{|c|}{12 Months } & \multicolumn{2}{|c|}{6 Months } & \multicolumn{2}{|c|}{12 Months } & \multicolumn{2}{|c|}{6 Months } & \multicolumn{2}{|c|}{12 Months } & \multicolumn{2}{|c|}{6 Months } & \multicolumn{2}{|c|}{12 Months } \\
\hline & Mean & \pm SD & Mean & $\pm \mathrm{SD}$ & Mean & $\pm \mathrm{SD}$ & Mean & \pm SD & Mean & $\pm \mathbf{S D}$ & Mean & $\pm \mathrm{SD}$ & Mean & $\pm \mathrm{SD}$ & Mean & \pm SD \\
\hline $\begin{array}{c}\text { Group } \\
\text { I }\end{array}$ & 0.49 & \pm 0.07 & 0.61 & \pm 0.23 & 0.34 & \pm 0.12 & 0.55 & \pm 0.13 & 0.55 & \pm 0.25 & 0.72 & \pm 0.45 & 0.47 & \pm 0.09 & 0.91 & \pm 0.37 \\
\hline $\begin{array}{c}\text { Group } \\
\text { II }\end{array}$ & 0.55 & \pm 0.19 & 0.72 & \pm 0.31 & 0.46 & \pm 0.14 & 0.67 & \pm 0.07 & 0.68 & \pm 0.12 & 1.08 & \pm 0.19 & 0.61 & \pm 0.23 & 0.95 & \pm 0.14 \\
\hline
\end{tabular}




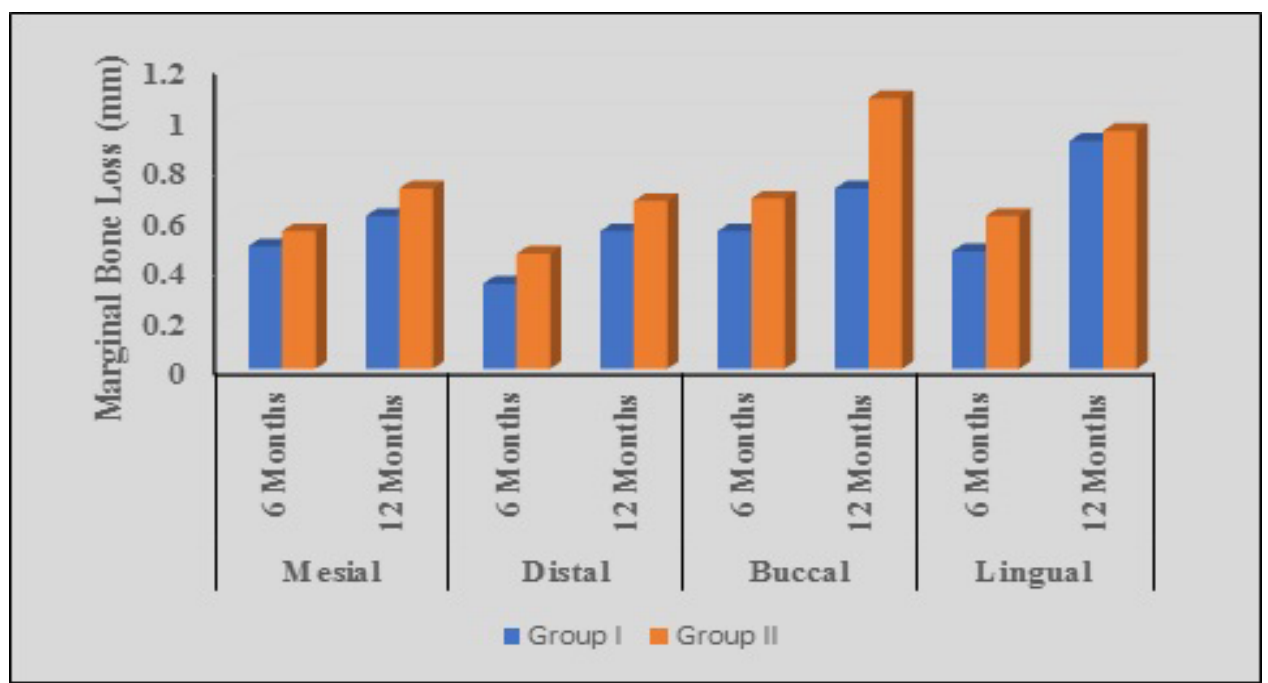

Figure 2: Marginal bone loss in bone groups during different time interval.

Comparison between group I and Group II using independent t-test showed no significant difference at six months and 12 months in the mesial, distal, buccal, and lingual sites $(p<0.05)$ (Table 2).
Within each group, the comparison between different times using one-way ANOVA with posthoc turkey test showed a significant difference in the bone loss values in 6 months and 12 months compared with the baseline values. However, the values of 6 months and 12 months were not significant with each other $(p<0.05)$. (Table 3 and 4 ).

Table 2: Comparison between the two groups at different sites after six months, 12 months follow-up time:

\begin{tabular}{|c|c|c|c|c|}
\hline Independent t-test & Time & $\mathbf{t}$ & $\mathbf{p}^{*}$ & Significance \\
\hline \multirow[t]{2}{*}{ Buccal } & 6 Months & 1.734 & 0.24 & Non-Significant \\
\hline & 12 Months & 1.734 & 0.95 & Non-Significant \\
\hline \multirow[t]{2}{*}{ Lingual } & 6 Months & 1.734 & 0.106 & Non-Significant \\
\hline & 12 Months & 1.734 & 0.14 & Non-Significant \\
\hline \multirow[t]{2}{*}{ Distal } & 6 Months & 1.734 & 0.38 & Non-Significant \\
\hline & 12 Months & 1.734 & 0.21 & Non-Significant \\
\hline \multirow[t]{2}{*}{ Mesial } & 6 Months & 1.734 & 0.06 & Non-Significant \\
\hline & 12 Months & 1.734 & 0.83 & Non-Significant \\
\hline
\end{tabular}

Table 3: One-way ANOVA with posthoc turkey test comparison between different times in Group I $(p<0.05)$ :

\begin{tabular}{|c|c|c|c|c|c|c|}
\hline $\begin{array}{c}\text { Dependent } \\
\text { Variable }\end{array}$ & (I) VAR00001 & (J) VAR00001 & $\begin{array}{c}\text { Mean Difference } \\
\text { (I-J) }\end{array}$ & Std. Error & $p$-value* & Significance \\
\hline \multirow[t]{3}{*}{ Buccal } & Baseline & 6 months & $-0.79000 *$ & 0.0951 & 0 & Significant \\
\hline & & 12 Months & $-0.71400 *$ & 0.0951 & 0 & Significant \\
\hline & 6 months & 12 Months & 0.076 & 0.0951 & 0.707 & Non-Significan \\
\hline \multirow[t]{3}{*}{ Lingual } & Baseline & 6 months & $-0.61000^{*}$ & 0.03181 & 0 & Significant \\
\hline & & 12 Months & $-0.57000 *$ & 0.03181 & 0 & Significant \\
\hline & 6 months & 12 Months & 0.04 & 0.03181 & 0.431 & Non-Significan \\
\hline \multirow[t]{3}{*}{ Mesial } & Baseline & 6 months & $-0.48900 *$ & 0.02427 & 0 & Significant \\
\hline & & 12 Months & $-0.49000^{*}$ & 0.02427 & 0 & Significant \\
\hline & 6 months & 12 Months & -0.001 & 0.02427 & 0.999 & Non-Significan \\
\hline \multirow[t]{3}{*}{ Distal } & Baseline & 6 months & $-0.34100 *$ & 0.04946 & 0 & Significant \\
\hline & & 12 Months & $-0.36200^{*}$ & 0.04946 & 0 & Significant \\
\hline & 6 months & 12 Months & -0.021 & 0.04946 & 0.906 & Non-Significan \\
\hline
\end{tabular}


Table 4: One-way ANOVA with post-hoc turkey test comparison between different times in group II $(p<0.05)$ :

\begin{tabular}{ccccccc}
\hline $\begin{array}{c}\text { Dependent } \\
\text { Variable }\end{array}$ & (I) VAR00001 & (J) VAR00001 & $\begin{array}{c}\text { Mean Difference } \\
\text { (I-J) }\end{array}$ & Std. Error & $p$ value* & Significance \\
\hline Buccal & Baseline & 6 months & $-0.68000^{*}$ & 0.05159 & 0.000 & Significant \\
& & 12 Months & $-0.63900^{*}$ & 0.05159 & 0.000 & Significant \\
& 6 months & 12 Months & 0.04100 & 0.05159 & 0.709 & Non-Significant \\
Lingual & Baseline & 6 months & $-0.46900^{*}$ & 0.10666 & 0.000 & Significant \\
& & 12 Months & $-0.39600^{*}$ & 0.10666 & 0.003 & Significant \\
& 6 months & 12 Months & 0.07300 & 0.10666 & 0.775 & Non-Significant \\
Mesial & Baseline & 6 months & $-0.45900^{*}$ & 0.04451 & 0.000 & Significant \\
& & 12 Months & $-0.42800^{*}$ & 0.04451 & 0.000 & Significant \\
& \multirow{3}{*}{ Distal } & 12 Months & 0.03100 & 0.04451 & .768 & Non-Significant \\
& Baseline & 6 months & $-0.55000^{*}$ & 0.05791 & 0.000 & Significant \\
& \multirow{2}{*}{6 months } & 12 Months & $-0.55900^{*}$ & 0.05791 & 0.000 & Significant \\
& & 12 Months & -0.00900 & 0.05791 & 0.987 & Non-Significant \\
\hline
\end{tabular}

\section{DISCUSSION}

Crestal bone loss around the neck of dental implants is still one of the most prevalent issues after implant placement and it has an impact on the implant's longterm effectiveness and crestal bone loss, which is essential for the long-term life of implants ${ }^{[21]}$. Surgical trauma and healing response, occlusal overload, peri-implantitis, micro gap, biologic width and implant crest module are the six primary reasons for crestal bone loss described in the literature $^{[22]}$

When the influence of implant diameter was considered, Mini implants produced the highest stresses and strains in both axial and off-axial loading when compared to conventional implants since the mini implants have a smaller surface area and volume, putting more stress per square millimetre against the bone than larger diameter implants ${ }^{[23]}$. However, the difference in the marginal bone loss was clinically insignificant ${ }^{[24]}$. A systematic review by Ma et al. ${ }^{[25]}$ showed that for early loaded implants, the average marginal bone loss was between 0 to $2 \mathrm{~mm}$ during the first year. A comparative study of seven patients having mandibular overdentures with two mini implants (Ø $2.8 \mathrm{~mm}$ diameter-ball attachments) showed no statistically significant difference in the bone density and bone height with those having two mini implants ${ }^{[26]}$.

There is debate over whether implant overdentures are beneficial or harmful in ridge reshaping after loading because of the denture's anterior anchorage in the symphyseal area, which preserves bone between implants, or because of the denture free movement posteriorly, which causes more resorption ${ }^{[27]}$.

When all the implants were put without CBCT, there is a risk of operator error in bone volume, shape and angulation. $\mathrm{CBCT}$ should be required as part of the treatment strategy and might be used as a long-term assessment reference. CBCT imaging of dental implants can also aid in the early diagnosis of bone loss and the correction of current implant problems before further deterioration occurs, with more accuracy than conventional radiographs ${ }^{[28]}$. Conventional intra-oral radiographs show interproximal alveolar bone levels, which suffers from anatomical superposition and geometric distortion. Even when highquality images are produced, conventional radiography has been shown to underestimate mild-to-moderate bone loss. In order to improve the sensitivity of conventional radiography in detecting marginal bone loss, digital subtraction radiography has been evaluated but has not reached common practice. The cone beam computerized tomography is recommended to assess the actual 3D configuration of marginal bone $\operatorname{loss}^{[29]}$. The International Commission on Radiological Protection (ICRP) guidelines for effective dose was $1000 \mu \mathrm{Sv}$ (Micro-Sievert) per year for public and $20,000 \mu \mathrm{Sv}$ for occupational ${ }^{[30]}$. The effective dose for the CBCT machine (CS 9500) used for this study is $136 \mu \mathrm{Sv}$ for a large field of view for adults, which equals 21 days of exposure to natural radiation, as was shown in a meta-analysis ${ }^{[31]}$.

The results of this study agree with Jofre et al. ${ }^{[32]}$ showed a significant difference in the pattern of bone loss between the splinted and non-splinted mini-implants. Vertical bone loss was seen in $51 \%$ of the mini-implant in the ball group and $29 \%$ in the bar group. The unsplinted ball group showed higher stress in a finite analysis. Splinting implants with a bar may distribute the functional stresses more evenly and extensively along with the implants ${ }^{[33]}$. Bar attachment seemed to be associated with reduced resorption of mandibular posterior alveolar ridges, which was explained by the dual mucosa-implant support provided by round bars that allow for unrestricted vertical movement of the prosthesis during function and transmit a variety of loads to the posterior edentulous region while putting little stress on the implants ${ }^{[34]}$. The study showed more bone resorption buccolingual, which can be explained by Li et al., who concluded that most areas that receive 
stresses in the implant-supported prostheses were the distal neck of the most distal implant ${ }^{[35]}$.

The use of a bar necessitates additional laboratory work, clinical procedures and a high cost for manufacturing if the bar fails; it typically necessitates replacing the overdenture $^{[36]}$. Ball attachments are simple, low-cost, easy to handle, simple to change without remaking the prosthesis and only need a few minutes of chair time to connect to the fixture. According to several authors, the ball attachment is the most often utilized attachment for unsplinted implants ${ }^{[37]}$. Abutment parallelism is essential for solitary implants because abutment non-parallelism causes attachment wear more quickly. As the number of implants increases, splinting becomes more critical as abutment parallelism becomes more challenging ${ }^{[38]}$.

\section{CONCLUSION}

Splinting of two mini-dental implants overdentures showed no difference in marginal bone loss with the unsplinted one. The results of both groups were within the accepted clinical levels of marginal bone loss.

\section{CONFLICT OF INTEREST}

The authors declare no conflict of interest.

\section{REFERENCES}

1. Lopez C, Saka C, Rada G, Valenzuela D. Impact of fixed implant supported prostheses in edentulous patients: protocol for a systematic review. BMJ open. 2016 ; $6(2): 1$ - 4 .

2. Mhatre S, Ram S, Mahadevan J, Karthik M. Rehabilitation of an edentulous patient with implant supported overdenture. J Contemp Dent 2013; 1: 52 - 6 .

3. Laurito D, Luca Lamazza, Spink M, DeBiase A. Tissue-supported dental implant prosthesis (overdenture): the search for the ideal protocol. A literature review. Annali di Stomatologia 2012; 3: 2 - 10 .

4. Almeida H, Santana E, Santos N, Moraes P, Araújo $\mathrm{Y}$, Gerbi M. Clinical aspects in the treatment planning for rehabilitation with overdenture and protocol-type prosthesis. Rev Gaúch Odonto 2015; 67: 71 - 6 .

5. Preoteasa E, Marina Imre, Lerner $\mathrm{H}$, Tancu A. Narrow Diameter and Mini Dental Implant Overdentures,In: Emerging Trends in Oral Health Sciences and Dentistry. $1^{\text {st }}$ ed. Rijeka: InTech; 2015. 242 p.
6. Tu C. Using mini dental implants to improve the stability of an existing mandibular complete denture in apatient with severe ridge resorption. J Prosthodont Implantol. 2012; 1: 48 - 52.

7. Azzaldeen A, Ahmet A, Ismail H, Georges C, Muhamad A-H. Immediate loading with mini dental implants in the fully edentulous mandible. Implant dentistry. 2015; 2 (4): 1490 - 9.

8. Mark J, Feine T, Exley C, Moynihan P, Müller F, Naert I, et al. The York Consensus Statement on Implant-Supported Overdentures Eur J Prosthodont Rest Dent. 2009; 17: 164 - 5.

9. Thomason J, Kelly S, Bendkowski A, Ellis J. Two implant retained overdentures--a review of the literature supporting the megill and york consensus statements. J Dent. 2012; 40: 22 - 34.

10. Lee J, Kim H, Shin S, Bryant S. Number of implants for mandibular implant overdentures: a systematic review. J Adv Prosthodont. 2012; 4: 204 - 9.

11. Jofre J, Castiglioni $\mathrm{X}$, Lobos C. Influence of minimally invasive implant-retained overdenture on patients' quality of life: a randomized clinical trial. Clin Oral Implants Res. 2013; 24 (10): 1173 - 7.

12. Catalan A, Mart'inez A, Marchesani F, Gonzalez U. Mandibular overdentures retained by two miniimplants: A seven-year retention and satisfaction study. J Prosthodont. 2015; 1: 1 - 7.

13. Morneburg T, Proschel P. Success rates of microimplants in edentulous patients with residual ridge resorption. Int $\mathbf{J}$ Oral Maxillofac Implants. 2008; 23 (2): 270 - 6.

14. Souza R, Ribeiro A, Vecchia M, Costa L, Cunha $\mathrm{T}$, Reis A, et al. Mini vs. standard implants for mandibular overdentures: A randomized trial. J Dent Res. 2015; 94: 1376 - 81.

15. Cho S, Froum S, Tai C, Young Cho, Elian $\mathrm{N}$, Tarnow D. Immediate loading of narrowdiameter implants with overdentures in severely atrophic mandibles. Pract Proced Aesthet Dent. 2007; 19: 1 - 8 .

16. Amato F, Polara G. The use of narrowdiameter dental implants to support mandibular overdentures: A prospective clinical study. J Impl Reconstr Dent. 2016; 6: 1 - 11. 
17. Rutkunas V, Mizutani H, Takahashi H. Influence of attachment wear on retention of mandibular overdenture. J Oral Rehabil. 2007; 34 (1): 41 - 51.

18. Pigozzo M, Mesquita $M$, Henriques G, Vaz L. The service life of implant-retained overdenture attachment systems. J Prosthet Dent. 2009; 102 (2): 74 - 80.

19. Misch C. Contemporary Implant Dentistry. 3rd ed. Missouri: Mosby Elsevier; 2008. 301 p.

20. Bajaj S, Rani S, Issar G, Sethi U, Kumar S, Mishra S. Comparative evaluation of crestal bone levels around endosseous implants as influenced by conventional and diode laser during secondstage surgery in mandibular implant-supported overdenture: An in vivo study. J Ind Prosthodont Soc 2020; 20 (1): 52 - 60 .

21. Shalash M, Abdalsamad A. Crestal bone loss around tissue level implants with platform matching abutments versus bone level implants with conical/platform switched abutments in the posterior mandible: a comparative study. Bull Natl Res Cent (Egypt). 2020; 44 (1): 184.

22. Hildebolt C, Couture R, Garcia N, Dixon D, Miley $\mathrm{D}$, Shannon $\mathrm{W}$, et al. Alveolar bone measurement precision for phosphor-plate images. Oral Surg Oral Med Oral Pathol Oral Radiol Endod. 2009; 108 (3): e96 - 107

23. Patil PG, Seow L, Uddanwadikar R, Ukey P. Biomechanical behavior of mandibular overdenture retained by two standard implants or 2 mini implants: A 3-dimensional finite element analysis. J Prosthet Dent $2021 ; 125$ (1): 138.e1 - .e8.

24. Abdallah H. Effect of using two splinted miniimplants versus two conventional implants retaining mandibular overdenture on crestal bone loss. Egypt Dent J. 2018;64(Issue 3 - July (Fixed Prosthodontics, Dental Materials, Conservative Dentistry \&amp; Endodontics)): 2793 - 805.

25. Ma S, PayneA. Marginal bone loss with mandibular two-implant overdentures using different loading protocols. Int J Prosthodont 2010; 23: 117 - 26.

26. Beyari M. Comparative study between two types of implants supporting mandibular overdenture. Int J Surg Res. 2015; 4: 15 - 8 .

27. Khalifa A, Wada M, Ikebe K, Maeda Y. To what extent residual alveolar ridge can be preserved by implant? A systematic review. Int $\mathrm{J}$ Implant Dent. 2016; 2: 22.
28. Dwingadi E, Soeroso Y, Lessang R, Priaminiarti M. Evaluation of Alveolar Bone on Dental Implant Treatment using Cone Beam Computed Tomography. Pesquisa Brasileira em Odontopediatria e Clínica Integrada. 2019; 19.

29. Ritter L, Elger M, Rothamel D, Fienitz T, Zinser $\mathrm{M}$, Schwarz F, et al. Accuracy of peri-implant bone evaluation using cone beam CT, digital intra-oral radiographs and histology. Dento maxillo facial radiology. 2014; 43 (6): 20130088-.

30. White S, Pharoah M. Oral Radiology Principles and Interpretation. 7th ed. Missouri: Elsevier; 2013. 31 p.

31. Ludlow J, Timothy R, Walker C, Hunter R, Benavides E, Samuelson D, et al. Effective dose of dental CBCT-a meta analysis of published data and additional data for nine CBCT units. Dento maxillo facial radiology. 2015; 44 (1): 20140197.

32. Jofre J, Cendoya P, Munoz P. Effect of splinting mini-implants on marginal bone loss: a biomechanical model and clinical randomized study with mandibular overdentures. Int $\mathrm{J}$ Oral Maxillofac Imp 2010; 25 (6): 1137 - 44.

33. Fouad M, Hegazy A. Bone height changes around immediately loaded implants splinted with pre- fabricated bar attachment for mandibular overdentures. Cairo Dent J. 2009; 25: 375: 86.

34. Emera R, Nabil H. Splinting of Mini Implants Used to Assist Complete Mandibular Overdentures with Two Different Bar Designs: A 3-Year Clinical and Radiographic Study. Azhar Dent J (Girls). 2019; 6 (1): 67 - 77.

35. Li K, Xin H, Zhao Y, Zhang Z, Wu Y. Remodeling of the Mandibular Bone Induced by Overdentures Supported by Different Numbers of Implants. J Biomech Eng. 2016; 138 (5): 051003.

36. Lambade D, Lambade P, Gundawar S. Implant supported mandibular overdenture: A viable treatment option for edentulous mandible J Clin Diagn Res. 2014; 8: 4 - 6.

37. Al-qutaibi A. Attachments used with implant supported overdenture. Adv Dent and Oral Health 2016; 1: 1 - 5 .

38. Bansal S, Aras M, Chitre V. Guidelines for treatment planning of mandibular implant overdentureJ. J Dent Implant. 2014; 4: 86 - 90. 